\title{
Acoustic Characterization of Sensors used for Marine Environmental Monitoring
}

Emma Cotter ${ }^{1}$ (corresponding author, ecotter@uw.edu)

Paul Murphy¹ (pgmurphy@uw.edu)

Christopher Bassett ${ }^{2}$ (cbassett@uw.edu)

Benjamin Williamson ${ }^{3,4}$ (benjamin.williamson@uhi.ac.uk)

Brian Polagye ${ }^{1}$ (bpolagye@uw.edu)

${ }^{1}$ University of Washington Department of Mechanical Engineering, Stevens Way, Box 352600, Seattle, WA, 98195, USA

${ }^{2}$ Applied Physics Laboratory, University of Washington, 1013 NE $40^{\text {th }}$ St, Box 355640, Seattle, WA, 98105, USA

${ }^{3}$ Environmental Research Institute, University of the Highlands and Islands (UHI), Ormlie Road, Thurso, KW14 7EE, UK

${ }^{4}$ School of Biological Sciences, University of Aberdeen, Tillydrone Avenue, Aberdeen, AB24 2TZ, UK 


\title{
Declarations of Interest
}

- None

\section{Highlights}

- Four underwater active acoustic sensors were characterized at frequencies $<160 \mathrm{kHz}$

- All sensors produced out-of-band acoustic emissions audible to marine mammals

- Emissions should not cause a temporary hearing threshold shift in any marine mammal

- Behavioral response is possible and should be considered in monitoring study design

\begin{abstract}
Active acoustic sensors are widely used in oceanographic and environmental studies. Although many have nominal operating frequencies above the range of marine mammal hearing, they can produce outof-band sound that may be audible to marine mammals. Acoustic emissions from four active acoustic transducers were characterized and compared to marine mammal hearing thresholds. All four transducers had nominal operating frequencies above the reported upper limit of marine mammal hearing, but produced measurable sound below $160 \mathrm{kHz}$. A spatial map of the acoustic emissions of each sonar is used to evaluate potential effects on marine mammal hearing when the transducer is continuously operated from a stationary platform. Based on the cumulative sound exposure level metric, the acoustic emissions from the transducers are unlikely to cause temporary threshold shifts in marine mammals, but could affect animal behavior. The extent of audibility is estimated to be, at most, on the order of $100 \mathrm{~m}$.
\end{abstract}

\section{Keywords}

Underwater acoustics; marine mammal hearing; active acoustic transducers; marine mammal monitoring

\section{Funding}

This work was funded by the US Department of Energy [grant number DE-EE0007827]. Emma Cotter is supported by a National Science Foundation Graduate Research Fellowship. 


\section{Introduction}

Active acoustic sensors are used for a variety of scientific purposes, including fisheries stock assessment (Fernandes et al., 2002; Simmonds and MacLennan, 2007), water current measurements (Thomson et al., 2012; Vennell, 1994), hydrographic surveys (Lundblad et al., 2006; Wilson et al., 2007), and marine mammal monitoring (Hastie et al., 2014; Lieber et al., 2017; Pyć et al., 2016; Wilson et al., 2007). The operational frequencies used by these sensors are driven by many factors, including scattering physics, acoustic attenuation rates, and study range. For example, in fisheries acoustics, lower frequency instrumentation $(<100 \mathrm{kHz}$ ) that allows for sampling at ranges of hundreds of meters is often used, while short-range imaging applications generally operate at higher frequencies. There are many advantages to using active acoustics in lieu of optical or passive acoustic sensors: they can operate when darkness, water conditions, or range may limit the use of optical cameras, and can detect marine animals when they are not vocalizing. However, if transducers produce sound within the range of marine mammal hearing, it may cause temporary or permanent hearing threshold shifts (NMFS, 2018) or affect their behavior if they are attracted to or avoid the source (Hastie, 2012; Southall et al., 2019).

The US National Marine Fisheries Service (NMFS) provides technical guidance to assess the effects of sound exposure on marine mammals, including definition of the hearing ranges of five groups of marine mammals (Table 1). Further, NMFS recommends that the cumulative sound exposure level (SEL $\left.L_{\text {cum }}\right)$ be used to assess the risk of hearing damage from non-impulsive sounds, and that sonars be treated as non-impulsive sources because their pulse durations are sufficient to reach a steady-state (NMFS, 2018). $S E L_{\text {cum }}$ uses an equal energy hypothesis and an auditory weighting function specific to each marine mammal hearing group to assess the cumulative impact that a source has on a marine mammal over time (Tougaard and Dähne, 2017). If $S E L_{\text {cum }}$ exceeds a hearing group-specific threshold (Table 1), a temporary threshold shift (TTS) in hearing may be expected. In extreme cases, a permanent threshold shift may occur.

For many applications, active acoustic sensors are mounted to a moving vessel and deployed for short periods. In this scenario, exposure levels for any individual animal will likely be low because an individual animal is unlikely to remain within the ensonified area for a long period. However, when continuous monitoring of a site is required, sensors may be operated for extended periods from a stationary platform (e.g., monitoring of a tidal turbine, as in [Williamson et al., 2016]). In these cases, a more careful consideration is required to evaluate exposure effects. If the source level of a transducer at maximum power input is known, then it can be calculated at other power levels as

$$
S L=S L_{\max }+10 \log _{10}\left(\frac{P}{P_{\max }}\right),
$$

where $S L_{\text {max }}$, in $\mathrm{dB}$ re $1 \mu \mathrm{Pa}$, is the source level (received level at a range of one meter) on-axis within the beam at $P_{\max }$, the maximum transmit power, and $S L$, in $\mathrm{dB}$ re $1 \mu \mathrm{Pa}$, is the source level at another transmit power, $P$. SEL cum for a receiver on-axis within the beam can then be calculated as

$$
S E L_{\text {cum }}=S L_{W}-20 \log _{10} R+10 \log _{10} \tau+10 \log _{10} n-\alpha R,
$$

where $S L_{w}$, in $\mathrm{dB}$ re $1 \mu \mathrm{Pa}$, is the weighted source level calculated by applying the auditory weighting function for a specific marine mammal hearing group to $S L$; $R$ is the range, in meters, from the transducer to the receiver; $\tau$ is the pulse duration, in seconds; $n$ is the number of pulses within an 
evaluation window; and $\alpha$ is the coefficient of absorption, in $\mathrm{dB} / \mathrm{m}$. $S E L_{\text {cum }}$ has units of $\mathrm{dB}$ re $1 \mu \mathrm{Pa}{ }^{2}-\mathrm{s}$. Estimating $S E L_{\text {cum }}$ when off-axis is more difficult as it requires either measurements of the beam pattern or an analytical model based on the geometry of the transducer (Medwin and Clay, 1997). For fisheries echosounders, if the nominal operating frequency lies within a marine mammal's hearing range (Table 1 ), this calculation is straightforward because the source level, pulse duration, and beamwidth are known through calibration (Demer et al., 2015).

If the nominal operating frequency is above a marine mammal's hearing range, there may still be acoustic emissions at lower frequencies (Deng et al., 2014; Hastie, 2012; Risch et al., 2017). This "out-ofband" sound can originate from sources such as "leakage" of the high-frequency signal to lower frequencies or sound associated with switching between transmit/receive modes or other sonar functions. Source levels for emissions at these frequencies, particularly as a function of position within the beam, are often not well-characterized, and out-of-band emissions may vary over the nominal pulse duration.

In this study, we characterize acoustic emissions from four active acoustic transducers: two multibeam sonars (one with two operating frequencies) and an acoustic Doppler current profiler (ADCP). As summarized in Table 2, the nominal operating frequencies of these transducers exceed the marine mammal auditory range. Acoustic emissions below $160 \mathrm{kHz}$, the upper limit of marine mammal hearing (NMFS, 2018), are characterized in the along-swath and across-swath directions. From these measurements, $S E L_{\text {cum }}$ is estimated throughout the sonar swath and the extent of audibility to each marine mammal hearing group is estimated. Acoustic emissions from one of the multibeam sonars (Tritech Gemini) have been previously characterized (Hastie, 2012) but are not presented in a manner that would allow $S E L_{\text {cum }}$ to be estimated. We are not aware of acoustic characterizations in the public domain for the other multibeam sonar (BlueView M900-2250) or acoustic Doppler current profiler (Nortek Signature 500). The methods presented in this paper can be used to assess other active acoustic sensors in a manner that allows for effective comparison between transducers and for the results to be used for environmental assessments.

Table 1: Hearing ranges and $S E L_{c u m}$ thresholds for TTS onset (SEL TTS) for five marine mammal hearing groups (NMFS, 2018)

\begin{tabular}{|l|l|l|}
\hline Group & Hearing range (kHz) & SEL $_{\text {TTS }}\left(\mathbf{d B}\right.$ re $\left.\mathbf{1} \boldsymbol{\mu P a} \mathbf{P a}^{2} \mathbf{s}\right)$ \\
\hline $\begin{array}{l}\text { Low-frequency cetaceans (baleen } \\
\text { whales) }\end{array}$ & $0.007-35$ & 179 \\
\hline $\begin{array}{l}\text { Mid-frequency cetaceans } \\
\text { (dolphins, toothed whales, beaked } \\
\text { whales, bottlenose whales) }\end{array}$ & $0.150-160$ & 178 \\
\hline $\begin{array}{l}\text { High-frequency cetaceans } \\
\text { (porpoises, Kogia, river dolphins, } \\
\text { Lagenorhynchus cruciger, L. } \\
\text { australis) }\end{array}$ & $0.275-160$ & 153 \\
\hline Phocid pinnipeds (seals) & $0.050-86$ & 181 \\
\hline $\begin{array}{l}\text { Otariid Pinnipeds (sea lions and fur } \\
\text { seals) }\end{array}$ & $0.060-39$ & 199 \\
\hline
\end{tabular}


Table 2: Evaluated active acoustic sensors, their nominal operating frequencies, an estimate of the extent of their nearfield, and their swath dimensions. Nominal operation frequencies and swath dimensions are specified by the manufacturers. The dimensions for the Nortek Signature 500 are for a single beam (the sensor has five diverging beams with the same axisymmetric beamwidth). Nearfield extent was estimated at the nominal operating frequency (Appendix A). Swath dimensions are also specified at the nominal operating frequency and are not expected to match those of out-of-band measurements.

\begin{tabular}{|c|c|c|c|c|c|c|}
\hline Type & Manufacturer & Sensor & $\begin{array}{l}\text { Nominal } \\
\text { operating } \\
\text { frequency } \\
(\mathrm{kHz})\end{array}$ & $\begin{array}{l}\text { Nearfield } \\
\text { extent }(\mathrm{m})\end{array}$ & $\begin{array}{l}\text { Along- } \\
\text { swath }\end{array}$ & $\begin{array}{l}\text { Across- } \\
\text { swath }\end{array}$ \\
\hline \multirow{2}{*}{ Multibeam Sonar } & \multirow{2}{*}{$\begin{array}{l}\text { Teledyne } \\
\text { BlueView }\end{array}$} & \multirow{2}{*}{ M900-2250 } & 900 & 3.4 & \multirow{2}{*}{$130^{\circ}$} & \multirow{2}{*}{$20^{\circ}$} \\
\hline & & & 2250 & 1.5 & & \\
\hline Multibeam Sonar & Tritech & Gemini 720is & 720 & 5 & $120^{\circ}$ & $20^{\circ}$ \\
\hline $\begin{array}{l}\text { Acoustic Doppler } \\
\text { Current Profiler }\end{array}$ & Nortek & Signature 500 & 500 & 1.2 & $2.9^{\circ}$ & $2.9^{\circ}$ \\
\hline
\end{tabular}

\section{Methods}

Evaluation of acoustic emissions was performed in two phases. First, an initial evaluation of each transducer was conducted to determine what, if any, sound it produced below $160 \mathrm{kHz}$ at the center of the swath (i.e., on-axis) and how that sound varied with transducer operating mode (e.g., intended operating range, power level). Second, across-swath and along-swath sweeps were conducted for each transducer at the operating mode associated with highest amplitude sound. All activities were performed in Portage Bay, Seattle, WA (freshwater, approximately $21^{\circ} \mathrm{C}$ ) on R/V Henderson, a 21-meter steel-hull catamaran vessel. The water depth at the test site was 5.1 meters and the water was quiescent, with no currents or waves. Two Ocean Sonics icListen HF hydrophones $(0.01-200 \mathrm{kHz}$ frequency range, $512 \mathrm{kHz}$ sample rate, standard GeoSpectrum hydrophone) were used to record sound from each transducer. The icListen uses a sigma-delta converter that samples at $16 \mathrm{MHz}$. Data are lowpass filtered (cut-off frequency of $250 \mathrm{kHz}$ ) to prevent aliasing and decimated to a sampling rate of 512 $\mathrm{kHz}$ (personal communication, Mark Wood, Ocean Sonics Ltd.).

An in-situ calibration of the hydrophones was conducted to determine their respective sensitivities in the direction of the active acoustic sources. The hydrophones were mounted in their measurement positions on R/V Henderson and an F41 acoustic projector with a traceable calibration was mounted at the same location as the active acoustic transducers under evaluation. Hydrophone sensitivities were estimated from 20 to $150 \mathrm{kHz}$ in $0.5 \mathrm{kHz}$ steps. Because the $\mathrm{F} 41$ transducer does not produce calibrated sound at frequencies below $20 \mathrm{kHz}$, sensitivities from $1 \mathrm{kHz}$ to $20 \mathrm{kHz}$ were taken from the manufacturer calibration, and sensitivities from 0.001 to $1 \mathrm{kHz}$ were taken from a third-party calibration by Ocean Networks Canada. Although the calibrations conducted at Ocean Networks Canada did not account for directionality, the manufacturer calibration suggests directionality is not significant at frequencies less than $20 \mathrm{kHz}$. It was necessary to move the hydrophones between the two measurement phases, which resulted in $\pm 5^{\circ}$ degree azimuthal uncertainty in their orientation. 


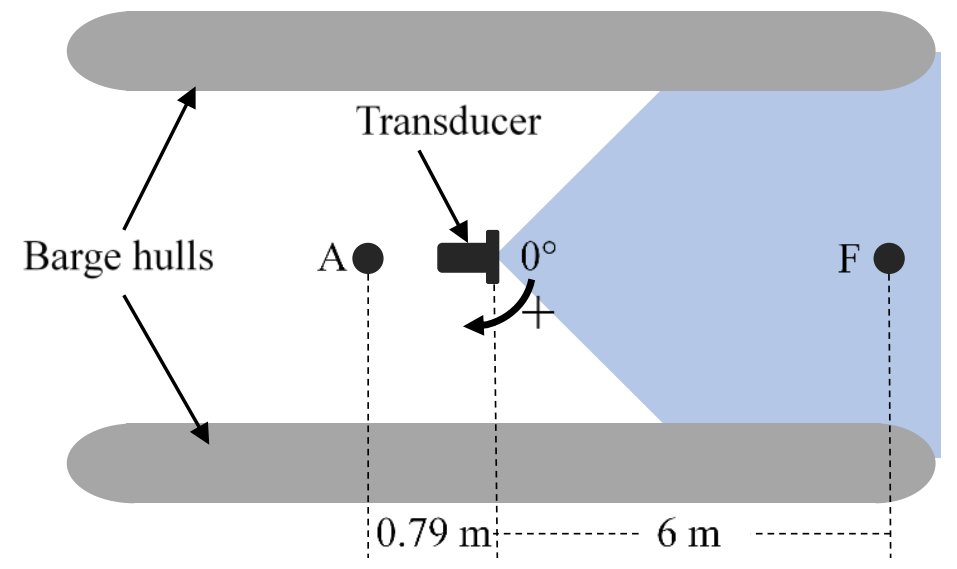

Figure 1: Test configuration (plan view; not to scale). "A" represents the aft hydrophone, and "F" represents the fore hydrophone. The blue swath represents the projection of a nominal swath from a transducer. The transducer and hydrophones were positioned below the barge hulls.

For the first phase of testing, each active acoustic sensor was mounted to a hydraulic ram between the hulls of the vessel, oriented towards the bow of the vessel, and lowered to a depth of 2.1 meters. The transducers were below the catamaran hulls at this depth. The multibeam sonars were oriented such that the along-swath direction was parallel to the water surface. The Gemini was mounted with a 10degree upward tilt to compensate for an internal 10-degree downward tilt. The Signature 500 was oriented such that the center (i.e., "vertical") beam was directly facing the hydrophone (all other beams were disabled during testing). The hydrophones were mounted to rigid posts and lowered below the hull of the vessel such that their transducers were at the same depth as the center of the beam. One hydrophone was mounted 6.0 meters directly in front of the active acoustic transducer ("fore hydrophone") and one hydrophone was mounted $0.79 \mathrm{~m}$ directly behind the active acoustic transducer ("aft hydrophone") (Figure 1). The fore hydrophone was in the acoustic far-field of all transducers at their nominal operating frequencies (see Table 2). Because the distance to the far-field is proportional to frequency for a fixed aperture (Medwin and Clay, 1997), the near-field at the frequencies reported in this paper $(<160 \mathrm{kHz})$ is expected to be smaller than the values presented in Table 2 (see further discussion in Appendix A). The aft hydrophone was not positioned in the far-field of all transducers, so source levels could not be calculated for this orientation. The test depth was fixed by the length of hydrophone cable, and the distances from the active transducer were fixed by hardware mounting points available on R/V Henderson.

As summarized in Table 3, both BlueView transducers (900 and $2250 \mathrm{kHz}$ ) were cycled through multiple power settings. The range setting of the Gemini was varied instead of power level, as the Gemini software (SeaTec) does not allow the power level to be adjusted. The Signature 500 was tested at its maximum transmit power with only the center beam enabled to prevent reverberation from the diverging beams, under the assumption that the other four beams have comparable acoustic characteristics. Manufacturer defaults were used for all other settings. At least 60 pings were recorded at each operating mode. The hydrophone data were monitored in real-time to avoid collecting data when ambient levels were elevated due to intermittent anthropogenic noise (e.g., vessel traffic), and data were collected at night when ambient noise was at a diurnal minimum. At least 30 seconds of ambient noise (no transducer pinging) was recorded between each test of transducer operating modes. 
Table 3: Transducer operating modes. Note that the range setting indicates the sensor operating setting, not the range at which received levels were measured.

\begin{tabular}{|c|c|c|c|}
\hline Sensor & Operating mode & $\begin{array}{l}\text { Range setting } \\
\text { (m) }\end{array}$ & $\begin{array}{l}\text { Pulse repetition } \\
\text { rate }(\mathrm{Hz})\end{array}$ \\
\hline \multirow{4}{*}{ BlueView (2250 kHz) } & $25 \%$ power level & 10 & 11.4 \\
\hline & $50 \%$ power level & 10 & 11.4 \\
\hline & $75 \%$ power level & 10 & 11.4 \\
\hline & 100\% power level & 10 & 11.4 \\
\hline \multirow{4}{*}{ BlueView (900 kHz) } & $50 \%$ power level & 50 & 3.3 \\
\hline & $70 \%$ power level & 50 & 3.3 \\
\hline & $85 \%$ power level & 50 & 3.3 \\
\hline & 100\% power level & 50 & 3.3 \\
\hline \multirow{3}{*}{ Gemini } & Default & 10 & 10 \\
\hline & Default & 50 & 10 \\
\hline & Default & 100 & 10 \\
\hline Signature 500 & $\begin{array}{l}\text { Single beam, } \\
\text { Maximum power } \\
\text { level }\end{array}$ & 47 & 8 \\
\hline
\end{tabular}

Table 4: Manufacturer-specified pulse duration at nominal operating frequency and estimated values from measurements.

\begin{tabular}{|c|c|c|c|}
\hline \multirow{2}{*}{\multicolumn{2}{|c|}{ Sensor }} & \multicolumn{2}{|c|}{ Pulse duration ( $\mu \mathrm{s})$} \\
\hline & & $\begin{array}{l}\text { Manufacturer- } \\
\text { specified }\end{array}$ & Observed \\
\hline \multicolumn{2}{|c|}{ BlueView (2250 kHz) } & 640 & 398 \\
\hline \multicolumn{2}{|c|}{ BlueView $(900 \mathrm{kHz})$} & 1,600 & 2,381 \\
\hline \multirow{3}{*}{ Gemini } & 10 meters & 12.2 & 184 \\
\hline & 50 meters & 88.3 & 328 \\
\hline & 100 meters & 177 & 328 \\
\hline \multicolumn{2}{|c|}{ Signature 500} & 673 & 1,678 \\
\hline
\end{tabular}



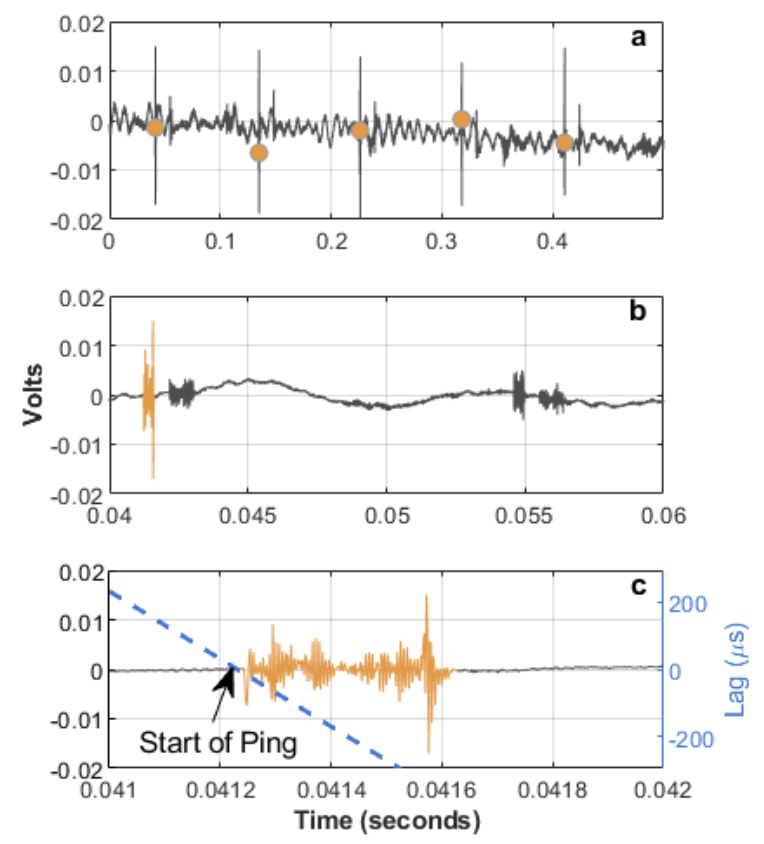

Figure 2: Sample voltage time series data from on-axis measurement of the $2250 \mathrm{kHz}$ BlueView at 100\% power. a) Approximate ping events detected in filtered data using an amplitude threshold (yellow circles). b) $20 \mathrm{~ms}$ window around one ping event, including the first arrival (yellow) and subsequent multi-path arrivals. Only the first arrival is used for subsequent analysis. c) Ping automatically detected using cross-correlation with the manually identified template signal. The dashed blue line shows the lag values at peak cross-correlation in the window.

Individual pings were isolated from the hydrophone data to characterize the sound generated by a transducer in a particular operating mode. For the first phase of testing, the first arrivals of 30 pings were isolated for each operating mode. This was done using a semi-automated process. A spectrogram of the recording window for each sonar mode was displayed to a human reviewer. From this, a relatively "clean" portion of the time series (e.g., no passing vessel traffic) was selected for processing. The reviewer then selected a frequency bin where the active transducer signal was clearly visible in the spectra to create a bandpass filter centered at the selected frequency with a passband and stopband that were 25 and $500 \mathrm{~Hz}$ wide, respectively. This filter was then applied to the voltage time series, and a threshold was manually selected to identify the approximate time of each ping in the filtered data, as shown in Figure 2a. All subsequent analysis was performed on the original, unfiltered data.

A 2 ms time window around an identified ping was then displayed, and the reviewer manually selected the start and end time. This produced a "template ping" used to isolate other pings in the time series. As shown in Table 4, the pulse durations of the pings observed in the measurements did not match the manufacturer-specified pulse durations. The discrepancy is likely because the manufacturer-specified pulse durations apply to the operating frequency of each instrument, while these measurements are limited to the bandwidth of the hydrophones. 
The template ping was used to isolate pings at each of the identified points in the filtered data using cross-correlation. The time window with the highest cross-correlation with the template ping was identified, and the lag value at the peak cross-correlation was taken to be the start of that ping, as shown in Figure 2c. After automatic detection, each ping was manually reviewed to ensure that the beginning of the ping was accurately located. Because surface reflections resulted in multiple arrivals of each ping (Figure $2 b$ ), the ping was shown to the reviewer in the context of the time series to ensure that only first arrivals were included in subsequent analysis. The same template ping was used for transducer operating modes expected to have the same ping profile (e.g., the same transducer operating at $50 \%$ and $100 \%$ power level). A representative ping from each transducer, received by the fore hydrophone, is shown in Figure 3.
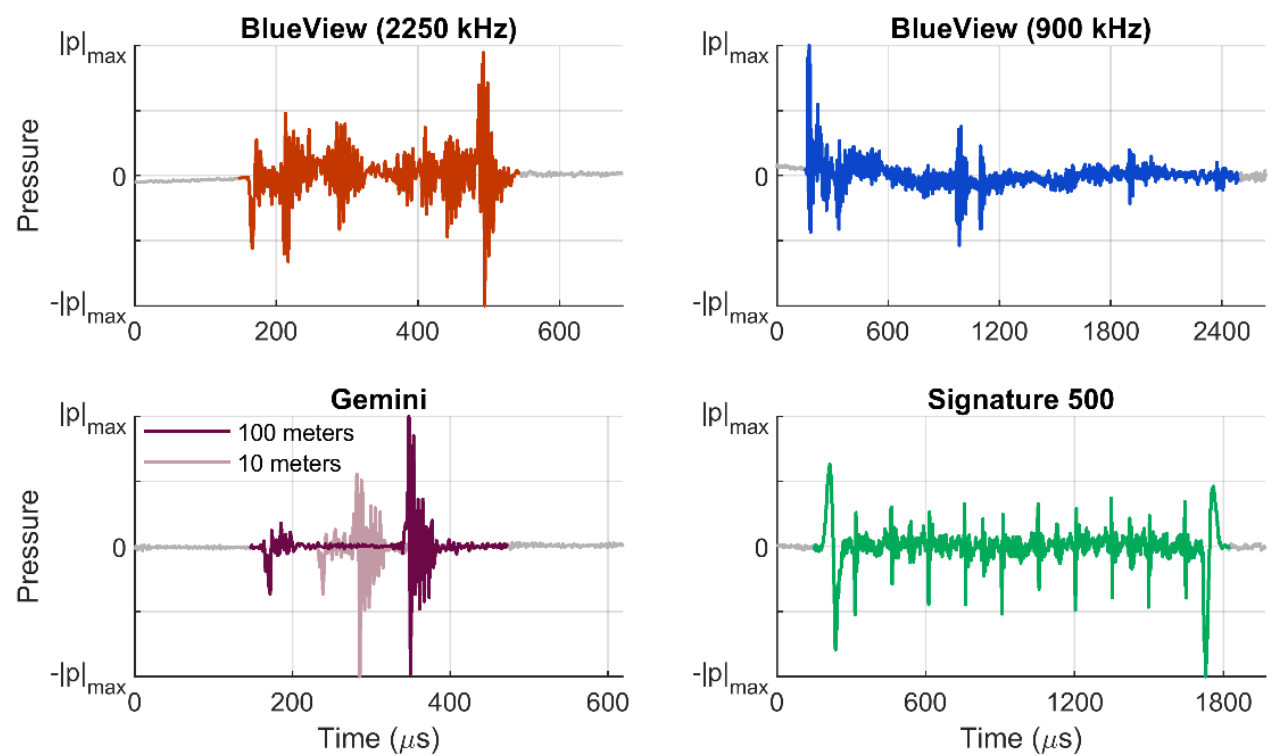

Figure 3: Representative on-axis pings from each transducer. For visualization, data are normalized by the peak absolute pressure in each time-series. 100\% power modes are shown for both BlueView transducers, and both 10 and 100-meter operating ranges are shown for the Gemini. The structure of the pings were approximately constant with varying power level for both BlueView transducers, as well as for the 50 and 100-meter range modes for the Gemini. Note that the time scale varies between plots because of varying ping duration.

The first arrivals of pings in the aft hydrophone data were automatically isolated by shifting the time window for each detected ping by the time difference of arrival between the two hydrophones using an estimated sound speed of $1486 \mathrm{~m} / \mathrm{s}$ (Marczak, 1997) and the separation distance from the forward face of the transducer.

The frequency content of each ping was calculated using a discrete Fourier transform (DFT). Because of the short pulse duration (300-2000 $\mu \mathrm{s})$, a window length equal to the size of the longest ping (the 900 $\mathrm{kHz}$ BlueView, at 1219 points) was used and a periodic Blackman taper applied. For pings with a pulse duration shorter than the window length, the data were zero-padded after tapering. This yielded the mean-square sound pressure, $p^{2}(f)$, in units of $\mathrm{Pa}^{2} / \mathrm{Hz}$ with a frequency resolution of $420 \mathrm{~Hz}$. The median and interquartile range of $p^{2}(f)$ were calculated for the 30 identified pings.

Fifteen seconds of ambient data were processed using the same approach as the ping data to allow sound during a ping to be compared to ambient noise. The mean-square sound pressure spectral density 
(PSD) of each ping, in $\mathrm{dB}$ re $1 \mu \mathrm{Pa}^{2} / \mathrm{Hz}$, was calculated by subtracting the ambient mean-square sound pressure spectrum recorded closest to each ping, $p_{a}^{2}(f)$ :

$$
P S D_{h}(f)=10 \log _{10}\left(\frac{p^{2}(f)-p_{a}^{2}(f)}{p_{r e f}^{2}}\right) .
$$

$P S D_{h}(f)$ is the PSD measured at the hydrophone, and $p^{2}$ ref is the reference pressure $\left(1 \mu \mathrm{Pa}^{2} / \mathrm{Hz}\right)$.

Fluctuations in ambient sound pressure did not contribute significantly to ping-to-ping variations in $P S D_{h}(f)$. Figure 4 compares the interquartile range of a 15-second window of ambient PSD recorded before each transducer was tested to the PSD measured immediately before each detected ping. This demonstrates that ambient PSD did not vary significantly during testing. The peak in the ambient PSD at $50 \mathrm{kHz}$ is likely associated with depth sounders from a nearby marina. Because pings that contained the $50 \mathrm{kHz}$ signal were discarded during manual review, this means that $P S D_{h}(f)$ is slightly over-corrected at this frequency. However, this is of limited consequence, as ambient PSD is at least a $10 \mathrm{~dB}$ below the source PSD of the active transducer pings for most frequencies (see Figure 5).
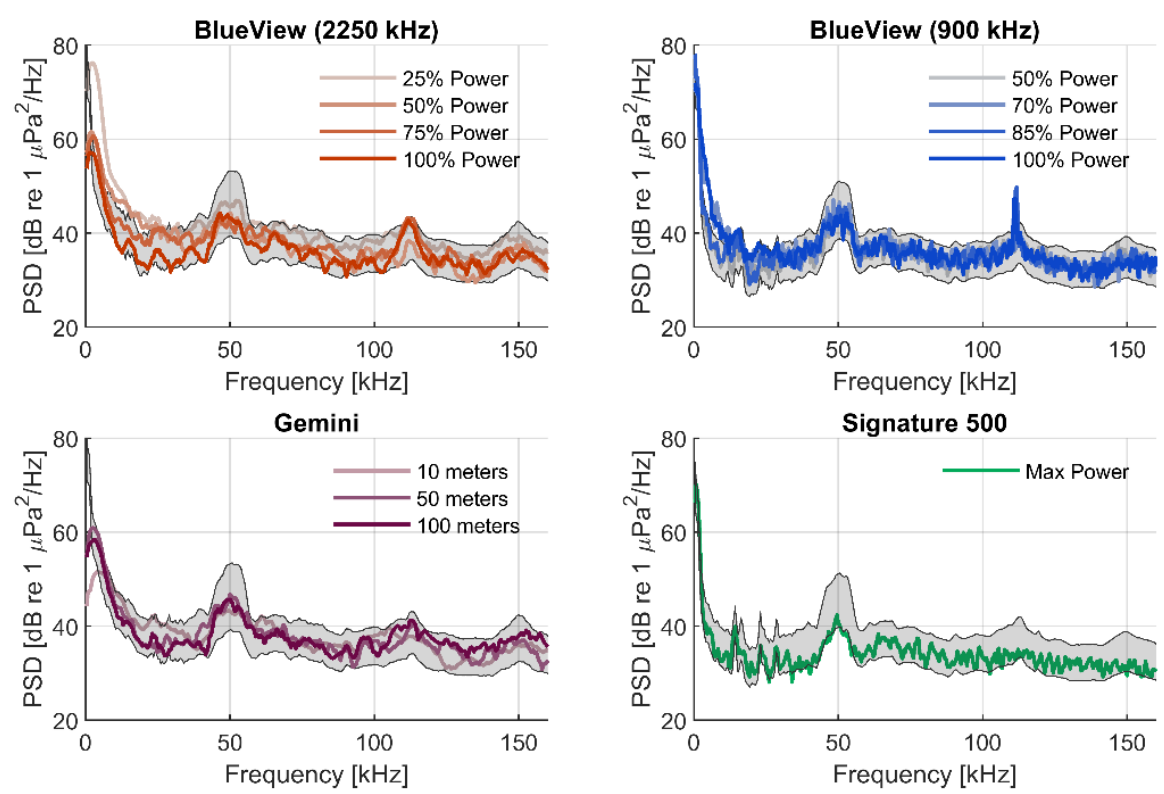

Figure 4: Variations in ambient sound during testing for each transducer. The grey shaded region depicts the interquartile range of the ambient PSD calculated for 15-second recordings before the test window. The colored lines indicate the median PSD calculated for the $3.9 \mathrm{~ms}$ (2000 points) preceding each detected ping.

$P S D_{h}(f)$ for the first arrival was extrapolated to the PSD at the source (received levels at a range of 1 meter) as:

$$
P S D(f)=P S D_{h}(f)+20 \log _{10} R_{h} .
$$

$P S D(f)$ is the source PSD, in $\mathrm{dB}$ re $1 \mu \mathrm{Pa}^{2} / \mathrm{Hz}$, and $R_{\mathrm{h}}$ is the range to the hydrophone (6 meters). Given that measurements were made in freshwater with a relatively short path length, absorption is negligible $(\alpha \approx 0)$. Specifically, absorption is approximately $5.4 \mathrm{~dB} / \mathrm{km}$ in freshwater at $21^{\circ} \mathrm{C}$ with a $\mathrm{pH}$ of 7.5 at the measurement depth of $2.1 \mathrm{~m}$, or $0.03 \mathrm{~dB}$ over the 6 meter measurement distance (Francois and Garrison, 1982a, 1982b), which is negligible in comparison to measurement accuracy. As previously 
discussed, a receiver at 1-meter range is in the far-field for all transducers at $160 \mathrm{kHz}$ except the Gemini, which has an estimated nearfield range of 1.1 meters at this frequency (see Appendix A).

$P S D(f)$ can be inverted to yield a source pressure distribution as:

$$
p_{s}^{2}(f)=p_{\text {ref }}^{2} 10^{P S D(f) / 10}
$$

Decidecade source levels (ISO/TC 43/SC 3 Underwater Acoustics, 2017), equivalent to one-third octave band source levels, were calculated as:

$$
S L_{d d e c}(f)=10 \log _{10}\left(\int_{f_{1}}^{f_{2}} \frac{p_{s}^{2}(f)}{p_{r e f}^{2}} d f\right)
$$

where $f_{1}$ and $f_{2}$ are the upper and lower frequencies of the band, respectively, and $S L_{\text {ddec }}(f)$ is in $\mathrm{dB}$ re 1 $\mu \mathrm{Pa}$.

The active acoustic sensors were rotated by the hydraulic ram to characterize variation in sound level in the across-swath and along-swath axes for the multibeam sonars, and across the beam of the Signature 500 (see Figure 1). To do this, the transducers and hydrophones were initially mounted in the same configuration as in the first phase of testing. The multibeam sonars were rotated 360 degrees in a clockwise direction, pausing every 5 degrees to record at least 30 pings. The ram was positioned with 0.02-degree precision. Within 10 degrees of the manufacturer-specified edge of the sonar swath, the angular resolution was doubled to 2.5 degrees to ensure that the edges of the swath were wellresolved. This test was repeated with the sonar swaths oriented parallel and perpendicular to the seafloor to characterize along-swath and across-swath variation, respectively. An error in hydrophone data acquisition resulted in a loss of data between $20^{\circ}$ and $35^{\circ}$ for the Gemini across-swath sweep (outside of the nominal swath width). Because the Signature 500 beam is relatively narrow compared to the multibeam sonars swaths, 1-degree resolution was used for the Signature 500, with the resolution increased to 0.5 degrees within one degree of the edge of the beam (the ram was positioned with 0.01degree precision). The Signature 500 beam pattern was assumed to be axisymmetric (Medwin and Clay, 1997), so only one orientation was tested. The raw Signature 500 beam pattern showed the peak in received levels shifted 0.5 degrees to the right. However, it was assumed that this shift was due to inaccuracy in positioning the Signature 500 on the hydraulic ram, and reported values were shifted so that the peak received level is at zero degrees rotation.

For these measurements, pings were detected in the time series data by the peak cross-correlation with the template ping. If fewer pings were detected than anticipated (e.g., near the edge of the swath as received levels decreased), a bandpass filter was applied to attempt to isolate pings in the data, following the methodology used to isolate pings in the on-axis measurements. Additionally, when the ping structure was observed to change within the swath, the reviewer was able to update the template ping (maintaining the same pulse duration). All pings were manually reviewed to ensure accuracy in ping selection. Ten pings were selected for analysis at each angular position, and $P S D(f)$ and $p_{s}{ }^{2}(f)$ were calculated for each ping at each position using equations 3-5.

The source level $(S L)$ of each ping, in $\mathrm{dB}$ re $1 \mu \mathrm{Pa}$ at $1 \mathrm{~m}$, was calculated from measurements as: 


$$
S L=10 \log _{10}\left(\int_{0}^{160 \mathrm{kHz}} \frac{p_{s}^{2}(f)}{p_{\text {ref }}^{2}} d f\right) .
$$

$S L$ for each angular position was defined as the median $S L$ of the 10 pings at that position, calculated in pressure-squared space.

Finally, the PSD at each angular position was used to estimate $S E L_{c u m}$ for each marine mammal group as a function of range and direction from the transducer. The auditory weighting function for each marine mammal hearing group, $W(f)$, was applied to the PSD for each position in the across-swath and alongswath sweeps to produce a weighted PSD, $P S D_{W} . W(f)$ was applied in log-space as:

$$
P S D_{W}(f)=W(f) P S D(f)
$$

A weighted source level, $S L_{w}$, in $\mathrm{dB}$ re $1 \mu \mathrm{Pa}$, was then calculated as:

$$
S L_{W}=10 \log _{10}\left(\int_{0}^{160 k H z} 10^{\frac{P S D_{W}}{10}} d f\right) .
$$

These weighted $S L_{w}$ values were used to calculate $S E L_{c u m}$, in $\mathrm{dB}$ re $1 \mu \mathrm{Pa}^{2}-\mathrm{s}$, at each angle and range, $R$, in meters, from the transducer by applying Equation 2 . The number of pulses, $n$, varies with the exposure time, $T$, as:

$$
n=T r
$$

where $r$ is the pulse repetition rate, in pulses per second, and $T$ is time in seconds. For example, the $2250 \mathrm{kHz}$ BlueView had a pulse repetition rate of $11.4 \mathrm{~Hz}$ with an observed pulse duration of $398 \mu \mathrm{s}$. After $T=1$ minute within the sonar swath, a marine mammal would be exposed $n=684$ pings. Calculation of $S E L_{\text {cum }}$ was repeated for exposure times from 0 to $10^{4}$ minutes (approximately 7 days) and for ranges from 1 to 20 meters. It was assumed that an animal makes no auditory recovery between pings (NMFS, 2018), and the absorption coefficient, $\alpha$, was calculated for representative conditions in seawater $\left(10^{\circ} \mathrm{C}, 35 \mathrm{psu}, \mathrm{pH} 8\right)$ at a depth of 10 meters. We note that these calculations assume an unobstructed acoustic path between source and receiver and neglect boundary interactions. In other words, these results would be accurate for a downward looking sonar in relatively deep water, but in shallower water or other sonar orientations, site-specific propagation modeling would be necessary to estimate the propagation loss. Results are presented in terms of the percentage of the TTS threshold ( $S E L_{T T S}$ in Table 1$)$ that is exceeded at a given position and exposure time $\left(\frac{S E L_{c u m}}{S E L_{T T S}}\right.$, calculated in pressuresquared space). In addition, the exposure time, $T_{T T S}$, that an animal would need to spend at a given location in the sonar swath before exceeding $S E L_{\text {TTS }}$ was calculated. The tables contained in NMFS (2018) were used for auditory weighting functions and TTS exposure thresholds.

Finally, $P S D(f)$ was used to estimate the maximum ranges at which marine mammals might be able to detect the sound produced by each sonar using the composite audiograms for each marine mammal hearing group derived in (NMFS, 2018) and representative ambient noise levels at sea state one (Wenz, 1962). A simple propagation model was used to predict the received level at varying ranges from the sonar: 


$$
R L=P S D(f)-20 \log _{10} R-\alpha(f) R .
$$

We assume that integration times play no role in audibility to provide a conservative estimate of hearing ranges (Erbe et al., 2016). This calculation was repeated for the PSD measured at each angular position within the beam. The absorption coefficient for each frequency, $\alpha(f)$, was calculated for representative conditions in seawater $\left(10^{\circ} \mathrm{C}, 35 \mathrm{psu}, \mathrm{pH} 8\right)$ at a depth of 10 meters, the same conditions used for $S E L_{\text {cum }}$ calculations. The sonar was considered to be no longer audible at the range where received levels at all frequencies and at all points in the beam fell below either the animal's hearing threshold or the ambient noise level. Because of the relatively low ambient noise levels, animal hearing thresholds were the determining factor in audibility for all frequencies and marine mammal hearing groups.

\section{Results}

\section{Acoustic Characteristics}

Figure 5 shows the median source $P S D$ and $S L_{d d e c}$ at 1 meter range from the transducer for pings measured by the fore hydrophone for each sonar operating mode at the center of the swath. The dashed, black line in each plot shows the ambient noise level during the test. All three sonars produced measurable sound within the range of marine mammal hearing in front of the transducer. For both BlueView transducers, the amplitude of the sound decreased non-linearly with power level setting, though the frequency content was independent of power level. For example, for the $2250 \mathrm{kHz}$ transducer, the decrease in source PSD from $75 \%$ to $50 \%$ power is smaller than the decrease from $50 \%$ to $25 \%$ (average decreases of $4 \mathrm{~dB}$ and $8 \mathrm{~dB}$, respectively), but the source PSD for the $75 \%$ and $100 \%$ power modes are similar. The same trend is observed for the $900 \mathrm{kHz}$ BlueView transducer. This nonlinear relationship between power level and source level is consistent with Equation 1.

The BlueView (both transducers) and Gemini also produced low-amplitude sound within the range of marine mammal hearing behind the transducer (aft hydrophone), most significantly for the $2250 \mathrm{kHz}$ BlueView. As with the fore measurement, PSD increased with power level for both BlueView transducers. For the Gemini, the 50-meter and 100-meter range modes again had similar PSDs, while the 10-meter range was not detectable above ambient noise behind the transducer. The Signature 500 also was not detectable behind the transducer. For all transducers, the received PSD behind the transducer ( $0.79 \mathrm{~m}$ range) did not exceed $20 \mathrm{~dB}$ above the ambient levels at any measured frequency. 
Source PSD
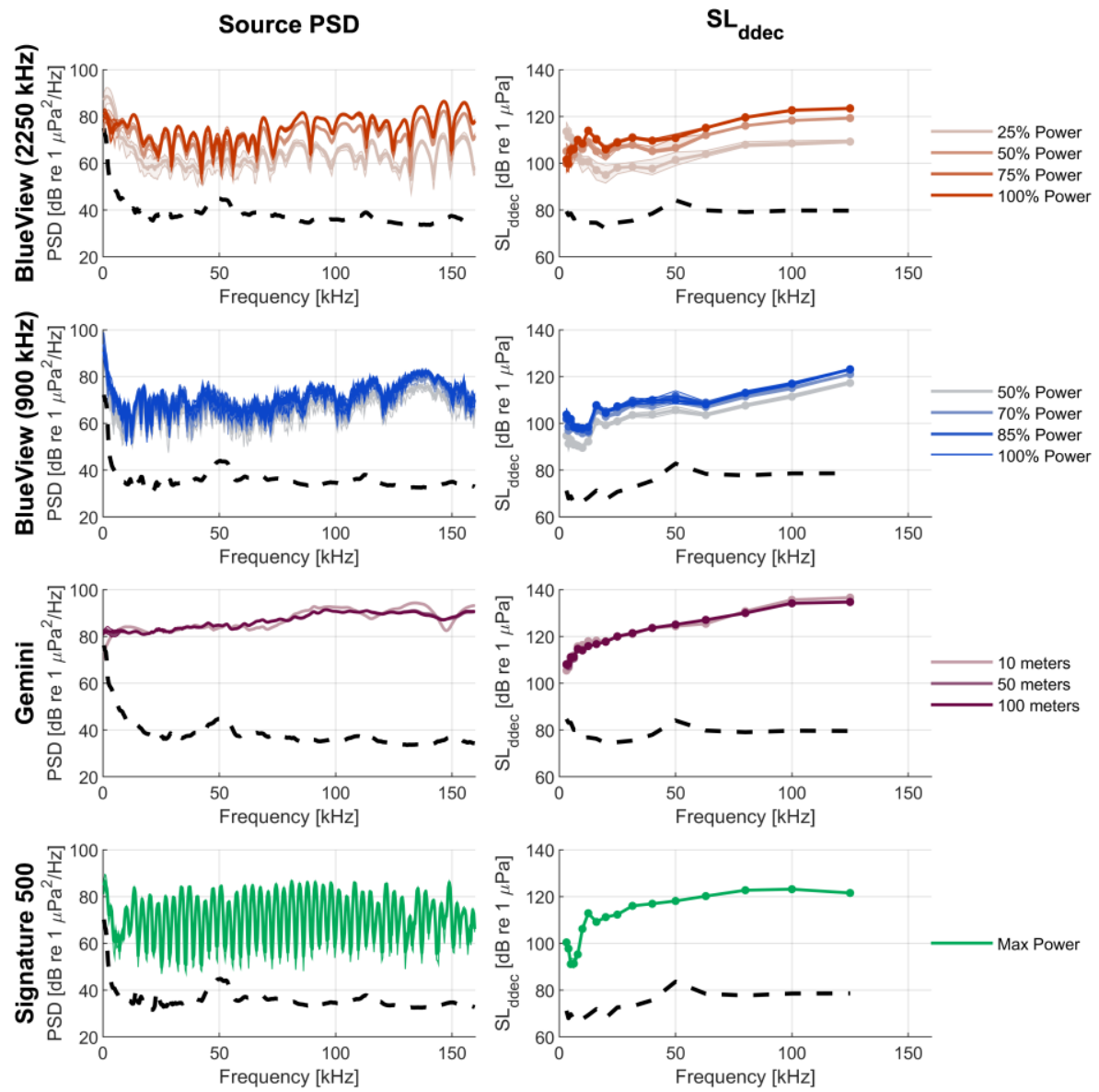

Figure 5: Median mean-square sound pressure spectral densities measured at the center of the sonar swath or Signature 500 beam for each transducer mode. The left-hand column shows the estimated PSD at one meter range from the transducer, and the right-hand column shows decidecade sound pressure levels at the same range. The shaded region indicates the interquartile range for all pings, and the dashed line indicates the ambient noise level recorded closest to each test. 


\section{Beam Patterns}
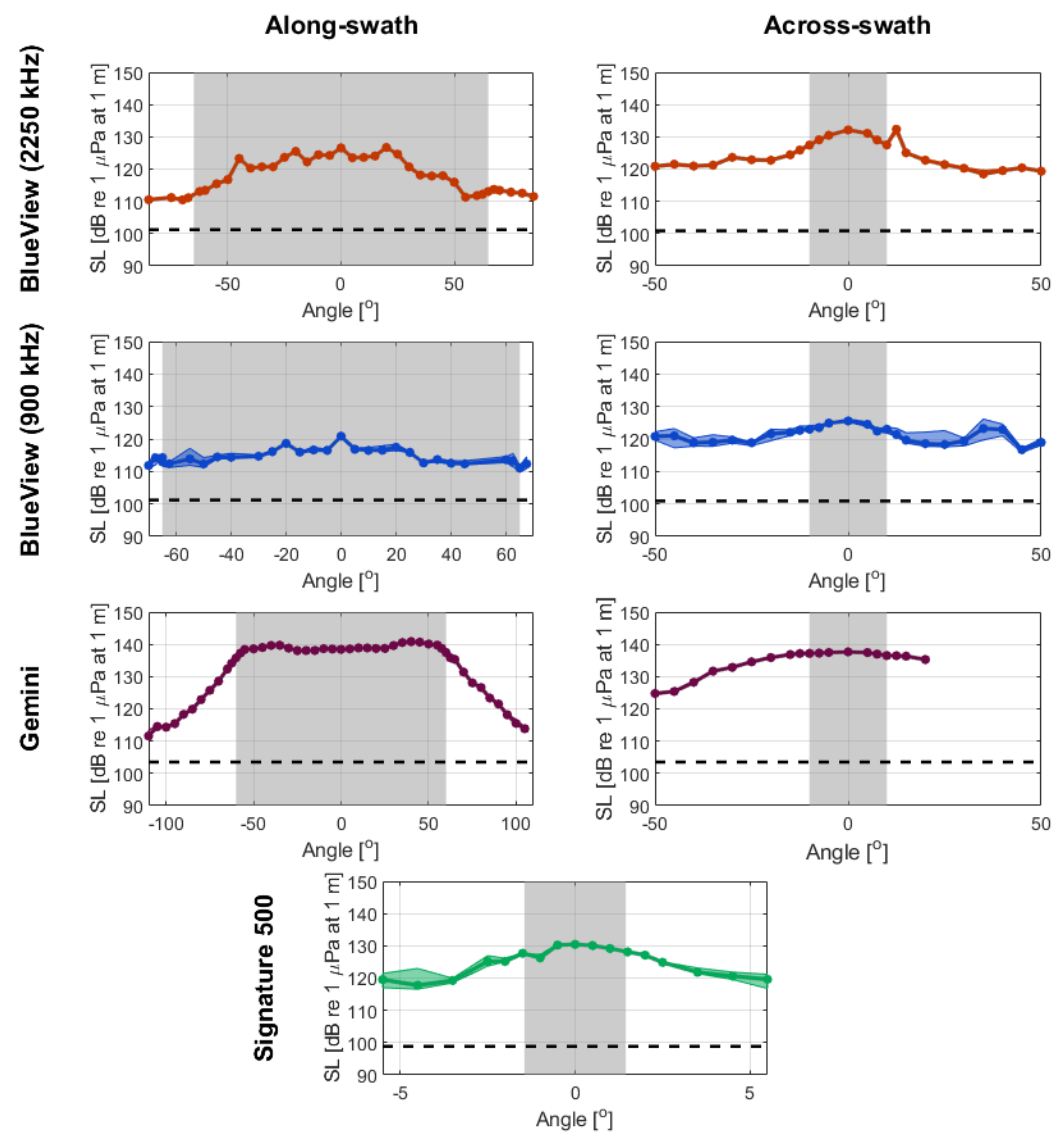

Figure 6: Median source level (unweighted, 0-160 kHz band) for ten pings recorded with the fore hydrophone at each orientation. The left-hand column shows the along-swath levels and the right-hand column shows the across-swath levels. The grey shaded region indicates the nominal swath or beamwidth of each transducer at the nominal operating frequency, and the colored shaded region indicates the interquartile range for the source level. The black dashed line indicates the ambient received level at the time of recording. The deviations between along-swath and across-swath measurements at $0^{\circ}$ are most likely attributable to alignment error in positioning the transducers (see Experimental Repeatability section).

Figure 6 shows the across-swath and along-swath variations in SL (Equation 7) for each sonar at the operating mode corresponding to the maximum $S L$. The dashed line indicates the median ambient level closest to the time of recording. Several observations can be made. First, for the BlueView and Gemini, $S L$ at the edge of the nominal swath is lower in the along-swath direction, and rolls off more quickly outside of the nominal swath in the along-swath direction than in the across-swath direction. Second, distinct trends can be observed in the beam pattern of each instrument. For the Signature 500 , the center is the highest-amplitude point and $S L$ rolls off towards the edge of the beam. As a consequence of increased transducer complexity in the along-swath direction, the Gemini and BlueView have greater variability. For the Gemini, the maximum $S L$ is observed near the edge of the swath. For the BlueView $2250 \mathrm{kHz}$, there are local maxima in $S L$ throughout the swath, likely because three synchronized transducers are used to produce a single acoustic image. Asymmetry in the beam pattern is likely due to angular positioning error in sensor mounting (e.g., $-5^{\circ}$ and $5^{\circ}$ were not equidistant from the center axis) and the relatively coarse resolution in across-swath and along-swath sweeps, such that sharp gradients within the swath may not have been resolved. 


\section{Experimental Repeatability}

Because the test set-up did not allow for precise sonar alignment, there is some inter-test variability. For example, the BlueView was removed and re-mounted to the hydraulic ram between the along-swath and across-swath characterization. This resulted in an increase in estimated $S L$ at the beam center in the vertical measurements. This indicates that the zero-degree position in the along-swath direction was not perfectly aligned with the corresponding zero-degree position in the across-swath position. Similarly, the source PSD curves reported for the different operating modes are at the nominal beam center in the across and along swath direction. This suggests that the measurements are sensitive to the precise position in the beam and that some results here may slightly under-report the peak values within the swath. More precise measurements could be obtained by a rigid mounting system directly coupling the active acoustic sensor to the hydrophone. 


\section{Cumulative Sound Exposure Level}
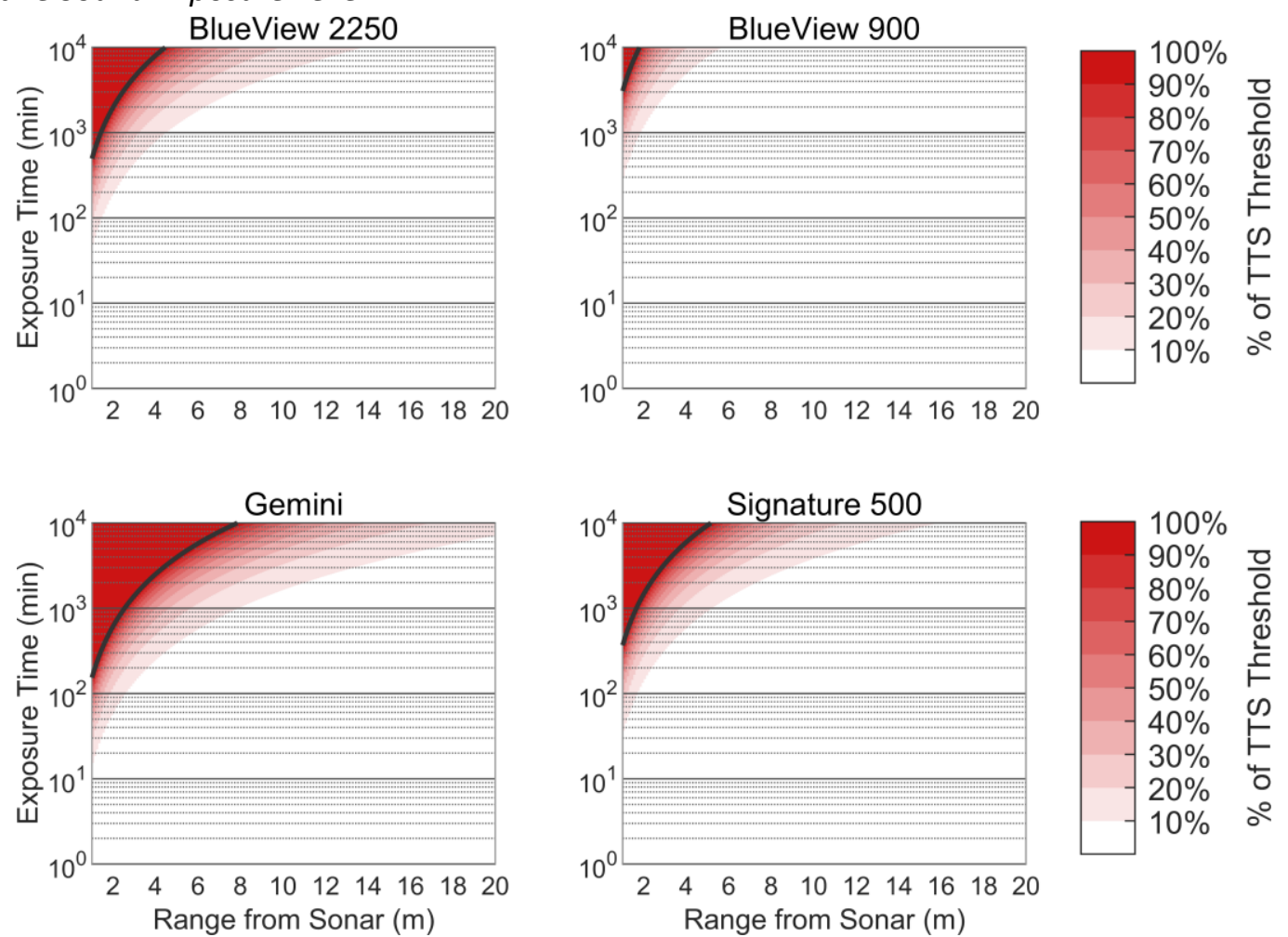

Figure 7: Percent of SEL $L_{\text {cum }}$ TTS threshold for high-frequency cetaceans, as a function of time and range from the sonar. The black line indicates $T_{T T S}$, the time at exceedance of the TTS threshold for a high-frequency cetacean in the portion of the swath with the highest source level.

Figure 7 shows the percentage of $S E L_{T T S}$ as a function of range and time spent at the angular position within the swath/beam with the maximum $S L$. We emphasize that these results are for a case in which boundary interactions are negligible. Results are only shown for high-frequency cetaceans, because they were the only one of the five NMFS marine mammal hearing groups that exceeded the TTS threshold within $T=1$ day of exposure (the maximum integration time recommended for a continuous source [NMFS, 2018]). Of the sonars tested, the Gemini could cause a temporary threshold shift in highfrequency cetaceans first, at approximately $T=2.6$ hours at 1 meter from the sonar. For context, at a range of $1 \mathrm{~m}$, the Gemini swath is only $35 \mathrm{~cm}$ in the along-swath direction, and therefore an animal larger than the ensonified area would need to remain stationary for 2.6 hours before experiencing TTS. The Signature 500, $2250 \mathrm{kHz}$ BlueView, and $900 \mathrm{kHz}$ BlueView would exceed the TTS threshold at 1meter range at approximately $6.1,8.3$, and $>24$ hours of exposure, respectively. 


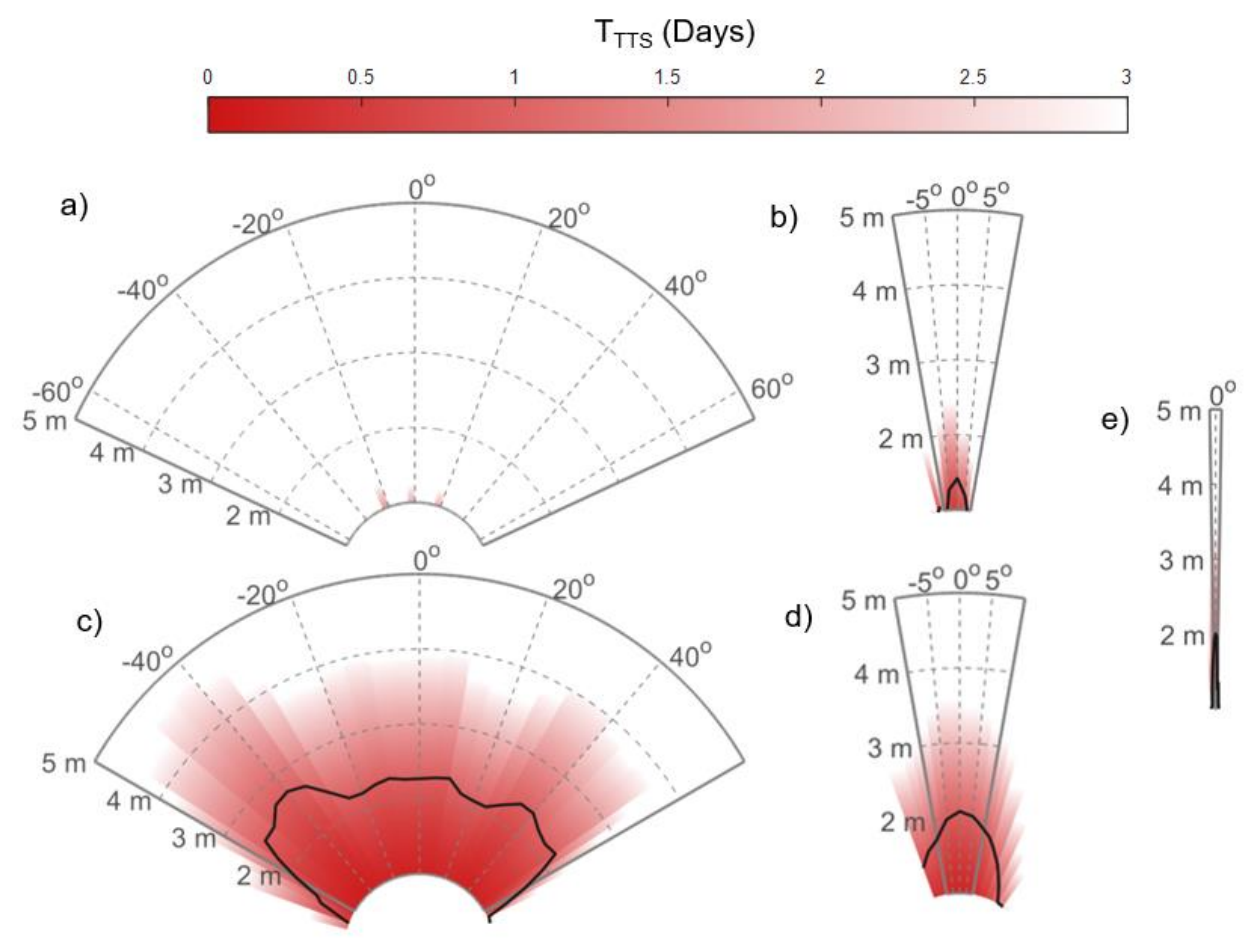

Figure 8: The exposure time, $T_{T T S}$, before the NMFS $S E L_{\text {cum }}$ threshold for high-frequency cetaceans is exceeded as a function of position relative to the transducer. All transducer swaths are shown to the same scale. The black line indicates where $T_{T T S}$ exceeds 24 hours. a) and b) show the along and acrossswath direction of the $2250 \mathrm{kHz}$ BlueView, respectively, c) and d) show the along and across-swath directions of the Gemini, respectively, and e) shows the symmetrical swath of the Signature 500. The 900 $\mathrm{kHz}$ BlueView is not shown because $T_{T T S}$ exceeds 24 hours at all ranges and positions. As for Figure 6 , the disparity between $T_{T T S}$ in the across- and along-swath orientations for the BlueView is most likely a consequence of a minor alignment error.

While all four of the transducers produced measurable sound within the range of marine mammal hearing, the $S E L_{\text {cum }}$ metric indicates that in an operational context, these transducers are unlikely to affect hearing sensitivity for any of the five marine mammal hearing groups when operated continuously from a stationary platform. Figure 8 shows the time, $T_{T T S}$, that a high-frequency cetacean would need to spend at a given point in the sonar swath before TTS is expected. The black line indicates the range where $T_{T T S}$ is equal to 1 day. The region of the swath where $T_{T T S}$ would be expected within 24 hours is less than $3 \mathrm{~m}$ for all sonars. For the Gemini, the transducer with the highest amplitude out-of-band emissions, the ensonified volume where $\mathrm{SEL}_{\text {cum }}$ exceeds the TTS threshold within one day is less than 5 $\mathrm{m}^{3}$. Even when considering that the Signature 500 is typically operated with 4 or 5 diverging beams, the comparable volume is less than $0.03 \mathrm{~m}^{3}$ because the individual beams are relatively narrow. While we have only presented the cumulative sound exposure level for the most sensitive marine mammal hearing group, the supplemental material can be used to calculate the cumulative sound exposure level for any of the five marine mammal hearing groups at any point in the beam when surface reflections are negligible. 


\section{Audibility to Marine Mammals}

Because the sound produced by these sonars is likely to be audible to marine mammals, is it possible that behavioral changes could occur, even when $S E L_{\text {cum }}$ is below the TTS threshold. Consequently, if active acoustic sensors are used for environmental monitoring of marine mammals, the potential for animal behavior to be affected by sonar emissions should be considered during study design and when interpreting results.

Table 5: Maximum range, in meters, at which a marine mammal from each hearing group may be able to detect each sonar.

\begin{tabular}{|l|c|c|c|c|c|}
\hline \multicolumn{1}{|c|}{ Sensor } & $\begin{array}{c}\text { Low- } \\
\text { frequency } \\
\text { cetaceans }\end{array}$ & $\begin{array}{c}\text { Mid- } \\
\text { frequency } \\
\text { cetaceans }\end{array}$ & $\begin{array}{c}\text { High- } \\
\text { frequency } \\
\text { cetaceans }\end{array}$ & $\begin{array}{c}\text { Otariid } \\
\text { pinnipeds }\end{array}$ & $\begin{array}{c}\text { Phocid } \\
\text { pinnipeds }\end{array}$ \\
\hline BlueView $(2250 \mathrm{kHz})$ & 82.5 & 27.0 & 53.0 & 9.5 & 52.0 \\
\hline BlueView $(900 \mathrm{kHz})$ & 41.0 & 12.0 & 34.0 & 3.5 & 14.0 \\
\hline Gemini & 20.0 & 29.5 & 108.5 & 4.5 & 21.5 \\
\hline Signature 500 & 61.5 & 33.0 & 68.0 & 7.0 & 30.0 \\
\hline
\end{tabular}

Table 5 lists the maximum range at which a marine mammal from each hearing group might be able to detect each sonar, given hearing thresholds and relatively low ambient noise. The Gemini could be audible to high-frequency cetaceans up to a range of 108.5 meters, the longest range at which any of the tested sonars might be detectable by a marine mammal. Counterintuitively, both BlueView transducers and the Signature 500 are audible to low-frequency cetaceans at a longer range than to mid-frequency cetaceans, and, in the case of the BlueView transducer, at a longer range than to highfrequency cetaceans. This can be attributed to the peaks in source level observed at low frequencies $(<$ $20 \mathrm{kHz}$ ) for these transducers (see Figure 5). At these frequencies, the composite audiograms for lowfrequency cetaceans suggest a higher sensitivity than for mid-frequency or high-frequency cetaceans. Further, we note that, for some hearing groups, the maximum range of audibility is similar to, or exceeds, the functional range of some of the multibeam sonars. In other cases, the maximum range of audibility is a small fraction of the sonar range.

These estimates are consistent with a previous study (Hastie, 2012) which showed that harbor porpoises (a high-frequency cetacean) changed their surfacing patterns in a pool when a Gemini was operated, out to a range of $40 \mathrm{~m}$. Because audibility is necessary, but not sufficient to cause behavioral change, the values in Table 5 should be taken as conservative estimates of the maximum range for potential changes in behavior. Further, the ambient noise levels in coastal environments, such as a marine energy site, would likely be higher than those considered here, resulting in reduced hearing ranges, and we recommend that a site-specific propagation be used to evaluate hearing ranges for specific conditions. For example, Hastie, (2012) estimated that the Gemini could be audible to harbor porpoises (a high frequency cetacean) to a range of only 60 meters at a tidal energy site.

\section{Conclusions}

The active acoustic transducers characterized in this study all have nominal operating frequencies above $500 \mathrm{kHz}$. While all of the transducers produced out-of-band sound audible by marine mammals (i.e., at frequencies less than $160 \mathrm{kHz}$ ) at some range, cumulative sound exposure levels are unlikely to cause hearing threshold shifts for any marine mammal group. If acoustic emissions could be a confounding 
factor for a behavioral study, we have shown that these may be decreased by adjusting the sonar operating mode. Overall, out-of-band sound should be considered when sonars are used to study marine mammals, but the measurements presented here show that these instruments should not raise regulatory concerns under current NMFS guidelines (2018).

\section{Supplemental Material}

The values of the PSD at the hydrophone $\left(P S D_{h}\right)$ measured at each angular position reported in this paper are contained in a Microsoft Excel spreadsheet that has been published on Mendeley Data. $P S D_{h}$ is calculated using Equation 3 and can be used determine $S E L_{\text {cum }}$ for any marine mammal exposed to the signal using the methods outlined in this paper or adjusted using range-dependent propagation losses and absorption for site-specific studies. All values are in $\mathrm{dB}$ re $1 \mu \mathrm{Pa}^{2} / \mathrm{Hz}$.

\section{Acknowledgements}

The authors wish to acknowledge Benjamin Brand for his assistance with the Acoustic Test Facility setup, Jessica Noe for her assistance designing sonar mounts, James Joslin for his assistance with cables for sonar operation, and Mark Wood for his assistance with icListen hydrophones. This study would not have been possible without their contributions. This work was funded by the US Department of Energy under DE-EE0007827. Emma Cotter is supported by a National Science Foundation Graduate Research Fellowship.

\section{Disclaimer}

This report was prepared as an account of work sponsored by an agency of the United States Government. Neither the United States Government nor any agency thereof, nor any of their employees, makes any warranty, express or implied, or assumes any legal liability or responsibility for the accuracy, completeness, or usefulness of any information, apparatus, product, or process disclosed, or represents that it would not infringe privately owned rights. Reference herein to any specific commercial product, process, or service by tradename, trademark, manufacturer, or otherwise does not necessarily constitute or imply its endorsement, recommendation, or favoring by the United States Government or any agency thereof. The views and opinions of authors expressed herein do not necessarily state or reflect those of the United States Government or any agency thereof.

\section{Works Cited}

Demer, D.A., Berger, L., Bernasconi, M., Bethke, E., Boswell, K.M., Chu, D., Domokos, R., Dunford, A., Fässler, S., Gauthier, S., Hufnagle, L.T., Jech, J.M., Bouffant, N., Lebourges-Dhaussy, A., Lurton, X., Macaulay, G.J., Perrot, Y., Ryan, T., Parker-Stetter, S., Stienessen, S., Weber, T., Williamson, N., 2015. Calibration of acoustic instruments, ICES Cooperative Research Report No. 326. https://doi.org/10.1016/j.optmat.2015.07.041

Deng, Z.D., Southall, B.L., Carlson, T.J., Xu, J., Martinez, J.J., Weiland, M.A., Ingraham, J.M., 2014. 200 kHz commercial sonar systems generate lower frequency side lobes audible to some marine mammals. PLoS One 9, 1-6. https://doi.org/10.1371/journal.pone.0095315

Erbe, C., Reichmuth, C., Cunningham, K., Lucke, K., Dooling, R., 2016. Communication masking in marine mammals: A review and research strategy. Mar. Pollut. Bull. 103, 15-38.

https://doi.org/https://doi.org/10.1016/j.marpolbul.2015.12.007 
Fernandes, P.G., Gerlotto, F., Holliday, V.D., Nakken, O., Simmonds, E.J., 2002. Acoustic applications in fisheries science: the ICES contribution. ICES Mar. Sci. Symp. 215, 483-492.

Francois, R.E., Garrison, G.R., 1982a. Sound absorption based on ocean measurements: Part I: Pure water and magnesium sulfate contributions. J. Acoust. Soc. Am. 72, 869-907. https://doi.org/10.1121/1.388170

Francois, R.E., Garrison, G.R., 1982b. Sound absorption based on ocean measurements. Part II: Boric acid contribution and equation for total absorption. J. Acoust. Soc. Am. 72, 1879-1890. https://doi.org/10.1121/1.388673

Hastie, G., 2012. Tracking marine mammals around marine renewable energy devices using active sonar. SMRU Ltd. Rep. URN 12D/328 to Dep. Energy Clim. Chang. 1-99.

Hastie, G., Gillespie, D., Gordon, J., Macaulay, J., McConnel, B., Sparling, C., 2014. Tracking Technologies for Quantifying Marine Mammal Interactions with Tidal Turbines: Pitfalls and Possibilities, in: Marine Renewable Energy Technology and Environmental Interactions. pp. 127-139.

ISO/TC 43/SC 3 Underwater Acoustics, 2017. ISO 18405: Underwater Acoustics - Terminology.

Lieber, L., Nilsen, T., Zambrano, C., Kregting, L., 2017. Optimising multiple multibeam sonars to assess marine life interactions with an underwater kite, in: Proceedings of the 12th European Wave and Tidal Energy Conference. Cork, Ireland, pp. 1-6.

Lundblad, E.R., Wright, D.J., Miller, J., Larkin, E.M., Rinehart, R., Naar, D.F., Donahue, B.T., Anderson, S.M., Battista, T., 2006. A benthic terrain classification scheme for American Samoa. Mar. Geod. 29, 89-111. https://doi.org/10.1080/01490410600738021

Marczak, W., 1997. Water as a standard in the measurements of speed of sound in liquids. J. Acoust. Soc. Am. 102, 2776-2779. https://doi.org/10.1121/1.420332

Medwin, H., Clay, C.S., 1997. Fundamentals of Acoustical Oceanography. Academic Press.

NMFS, 2018. 2018 Revision to: Technical Guidance for assessing the effects of anthropogenic sound on marine mammal hearing (Version 2.0): Underwater acoustic thresholds of permanent and temporary threshold shifts. U.S. Dept. Commer., NOAA. NOAA Tech. Memo. NMFS-OPR-59, 167 pp.

Pyć, C.D., Geoffroy, M., Knudsen, F.R., 2016. An evaluation of active acoustic methods for detection of marine mammals in the Canadian Beaufort Sea. Mar. Mammal Sci. 32, 202-219. https://doi.org/10.1111/mms.12250

Risch, D., Wilson, B., Lepper, P., 2017. Acoustic Assessment of SIMRAD EK60 High Frequency Echo Sounder Signals ( $120 \& 200 \mathrm{kHz}$ ) in the Context of Marine Mammal Monitoring, Scotish Marine and Freshwater Science Report. Marine Scotland Science. https://doi.org/10.7489/1978-1

Simmonds, J., MacLennan, D., 2007. Fisheries Acoustics: Theory and Practice, 2nd ed. Blackwell Publishing Ltd. https://doi.org/10.1002/9780470995303

Southall, B.L., Deruiter, S.L., Friedlaender, A., Stimpert, A.K., Goldbogen, J.A., Hazen, E., Casey, C., Fregosi, S., Cade, D.E., Allen, A.N., Harris, C.M., Schorr, G., Moretti, D., Guan, S., Calambokidis, J., 2019. Behavioral responses of individual blue whales (Balaenoptera musculus) to mid-frequency military sonar. J. Exp. Biol. 222, 1-15. https://doi.org/10.1242/jeb.190637

Thomson, J., Polagye, B., Durgesh, V., Richmond, M.C., 2012. Measurements of turbulence at two tidal 
energy sites in Puget Sound, WA. IEEE J. Ocean. Eng. 37, 363-374.

https://doi.org/10.1109/JOE.2012.2191656

Tougaard, J., Dähne, M., 2017. Why is auditory frequency weighting so important in regulation of underwater noise? J. Acoust. Soc. Am. 142, 415-420. https://doi.org/10.1121/1.5008901

Vennell, R., 1994. Acoustic Doppler Current Profiler measurements of tidal phase and amplitude in Cook Strait, New Zealand. Cont. Shelf Res. 14, 353-364.

Wenz, G.M., 1962. Acoustic Ambient Noise in the Ocean: Spectra and Sources. J. Acoust. Soc. Am. 34, 1936-1956.

Williamson, B.J., Blondel, P., Armstrong, E., Bell, P.S., Hall, C., Waggitt, J.J., Scott, B.E., 2016. A SelfContained Subsea Platform for Acoustic Monitoring of the Environment Around Marine Renewable Energy Devices-Field Deployments at Wave and Tidal Energy Sites in Orkney, Scotland. IEEE J.

Ocean. Eng. 41, 67-81. https://doi.org/10.1109/JOE.2015.2410851

Wilson, M.F.J., O'Connell, B., Brown, C., Guinan, J.C., Grehan, A.J., 2007. Multiscale Terrain analysis of Multibeam Bathymetry Data for Habitat Mapping on the Continental Slope. Mar. Geod. 30, 3-35. https://doi.org/10.1080/01490410701295962 


\section{Appendix A}

The nearfield extent of a line array transducer (used in both the BlueView and Gemini multibeam sonars) can be estimated by

$$
r=\frac{L^{2}}{\lambda}
$$

where $r$ is the extent of the nearfield, in meters, $L$ is the length or aperture of the transducer, in meters, and $\lambda$ is the wavelength of the measured sound waves (Medwin and Clay, 1997). Substituting $f=c \lambda$, where $f$ is the measured frequency, in $\mathrm{Hz}$, and $c$ is the speed of sound, in $\mathrm{m} / \mathrm{s}$,

$$
r=\frac{L^{2} f}{c} .
$$

This equation is used to estimate the nearfield extent at both the transducer nominal operating frequency and the highest measured frequency $(160 \mathrm{kHz})$ for the BlueView and Gemini in Table 6. For the Gemini, the manufacturer provided the nearfield extent estimate at the nominal operating frequency rather than the transducer aperture. This value was used to estimate the transducer aperture for the calculation at $160 \mathrm{kHz}$.

Medwin and Clay (1997) also provide an estimate for the nearfield of a circular piston transducer:

$$
r=\frac{\pi a^{2}}{\lambda}
$$

which can be equivalently expressed as

$$
r=\frac{\pi a^{2} f}{c}
$$

The latter equation is used to estimate the nearfield of the Signature 500 in Table 6 . An estimated speed of sound of $1486 \mathrm{~m} / \mathrm{s}$ (Marczak, 1997) is used for all calculations. Because the nearfield extent is proportional to the measured frequency, the nearfield extent for frequencies less than $160 \mathrm{kHz}$ will be smaller than the values reported in Table 6.

Table 6: Manufacturer provided information and calculation of nearfield extent estimations for each transducer at its operating frequency and at the highest frequency reported in this paper (160 kHz) based on Medwin and Clay, (1997).

\begin{tabular}{|l|l|c|c|}
\hline Instrument & $\begin{array}{l}\text { Manufacturer provided } \\
\text { information }\end{array}$ & $\begin{array}{l}\text { Nearfield extent at } \\
\text { operating frequency } \\
\text { (m) }\end{array}$ & $\begin{array}{l}\text { Nearfield } \\
\text { extent at 160 } \\
\mathbf{k H z}(\mathbf{m})\end{array}$ \\
\hline BlueView $(900 \mathrm{kHz})$ & $\begin{array}{l}\text { Transducer aperture, } L= \\
0.075 \mathrm{~m}\end{array}$ & 3.4 & 0.61 \\
\hline BlueView $(2250 \mathrm{kHz})$ & $\begin{array}{l}\text { Transducer aperture, } L= \\
0.032 \mathrm{~m}\end{array}$ & 3.4 & 0.11 \\
\hline Gemini $(720 \mathrm{kHz})$ & $\begin{array}{l}\text { Nearfield extends 5 meters } \\
\text { from transducer at } \\
\text { operating frequency }\end{array}$ & 5 & 0.17 \\
\hline Signature $(500 \mathrm{kHz})$ & $\begin{array}{l}\text { Circular piston transducer } \\
\text { with } a=0.033 \text { m radius }\end{array}$ & 1.2 & 0.37 \\
\hline
\end{tabular}

